\title{
Streamlining patient care from the emergency department to discharge: Proof of concept of an electronic neck of femur pathway
}

\author{
Alex Ward", Jonathan France ${ }^{* \#}$ and Nikhil Nanavati \\ Doncaster and Bassetlaw NHS Foundation Trust, Thorne Road, Doncaster DN2 5LT, UK \\ \#Both authors have contributed equally to this work
}

\begin{abstract}
Background: Femoral neck fractures are associated with a high mortality rate and the incidence is rising in the UK [1-3]. High quality evidence-based guidelines exist and are supported by financial incentives for trusts meeting set criteria though a best practice tariff (BPT) payment.

Hospital trusts submit data collected for their neck of femur patients to the national hip fracture database (NHFD) who support the BPT scheme. Compliance with these standards has been shown to be beneficial to patients reducing mortality and improving outcomes. Between 2015 and 2016 when these audits took place, the value of BPT increased from $£ 890$ to $£ 1353$ making compliance potentially more valuable.

Methods: In August 2016, an electronic pathway was introduced to a Trauma and Orthopaedic department in South Yorkshire. The rates of documentation and the compliance with the BPT criteria were audited for the seven months before and after introduction. Prior to the introduction, the audit was conducted by pulling a random selection of notes whilst the electronic pathway made the process much easier, allowing all pathways to be assessed for completeness.

Results: For the first audit, 79 patients' notes were pulled, with 221 pathways being analysed for the second. Following the introduction of the pathway the percentage achieving the tariff did reduce but it is likely artefact as only a third of pathways were audited.

Conclusion: Since the introduction of the electronic neck of femur pathway, completion rates of documentation have increased. This means there is the potential for patient care to have improved. Due to the limited number of notes being pulled as part of the initial audit we are unable to say whether the pathway has improved the rates of BPT achievement but further audits will be able to show this. At present the electronic pathway is being advertised on the NHFD website and will be trialled at other sites.
\end{abstract}

\section{Introduction}

Neck of femur fractures (NOF) carry a high mortality with 20 to $35 \%$ of sufferers dying within one year and the resulting morbidity being serious, including deep venous thrombosis, pulmonary embolus and infection [1-3]. With around 90,000 patients [4] suffering this injury each year, a Best Practice Tariff (BPT) has been created with the express purpose of standardising and improving patient care and, as a result, improving patient outcomes [1]. Alongside the improved individual outcomes, the introduction the BPT also is invaluable for trusts across the country due to its potentially increased revenue. Units "treating 350 hip fractures per year with $90 \%$ meeting requirements" could result in an extra " $£ 140,000$ of additional income" for the trust and funding for other services [5]. At present, all patients diagnosed with a NOF have their details uploaded to the National Hip Fracture Database (NHFD), with 64,864 being uploaded in 2015 alone [6]. Between 2015 and 2016 when these audits took place, the value of BPT increased from $£ 890$ to $£ 1353$ making compliance potentially more valuable (Figure 1).

With the increasing focus on patient centred care, as well as the financial situation of the NHS being more stretched than ever before, the creation of an electronic pathway to streamline the care of NOF patients was undertaken. By allowing the emergency department, surgical team and the orthogeriatricians to document their care in the same place, it was felt a more integrated approach to fulfilling all aspects of the BPT could be achieved. Following its introduction, the pathway was audited against the previous paper system.

\section{Materials and Methods}

Using the pre-existing clerking booklet, an electronic pathway was created, including a traditional template with additional sections focussing on the information required by the NHFD such as use of use of nerve blocks and Nottingham Hip Fracture Score. The pathway was created using a multi-disciplinary approach, with sections for the emergency department, clerking senior house officer, operating surgeon and the orthogeriatrician to complete. By each section requiring input and being linked to a subsection of the BPT, the pathway has the

Correspondence to: Jonathan France, Doncaster and Bassetlaw NHS Foundation Trust, Thorne Road, Doncaster DN2 5LT Jonathan France Core Surgical Trainee Department of Trauma and Orthopaedics Doncaster and Bassetlaw NHS Foundation Trust, Thorne Road, Doncaster DN2 5LT Alex Ward Core Surgical Trainee Department of Trauma and Orthopaedics, Doncaster and Bassetlaw NHS Foundation Trust, Thorne Road, Doncaster DN2 5LT Nikhil Nanavati Specialist Registrar Department of Trauma and Orthopaedics, UK, E-mail: mda09jf@gmail.com

Received: March 13, 2018; Accepted: March 19, 2018; Published: March 30 2018 


\section{BPT Achieved (\%)}

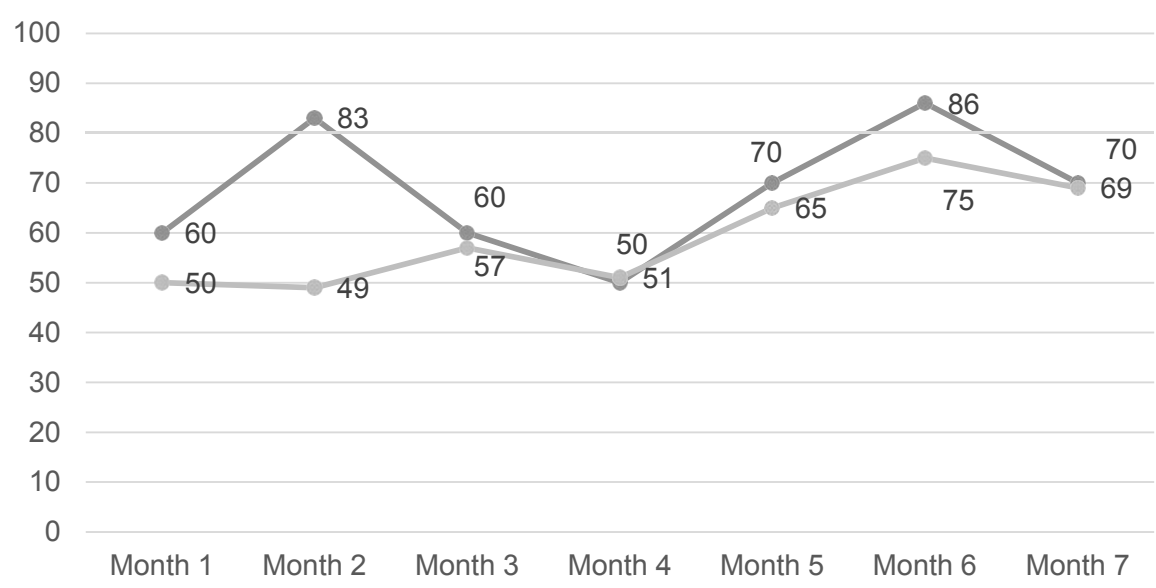

Figure 1. Achievement of Best Practice Tariff (Pre-introduction (dark grey) and Post-introduction (light grey)).

potential to ensure compliance with clinical guidance. By developing the interface to be user friendly, the pathway is accessible for all users, no matter what their information technology skills.

Following the electronic NOF pathways introduction in August 2016, a closed loop audit comparing its efficacy and completion rates to a selection of paper based forms was performed. Prior to the introduction, the seven-month audit period was conducted by pulling a random selection of notes whilst the electronic pathway made the process much easier, allowing all pathways to be assessed for completeness. Sessions were run within the department to educate the junior doctors on the use of the pathway prior to the reaudit. As well as looking at the documentation rates, the compliance of patients going to theatre within thirty- six hours and being reviewed by an orthogeriatrician within seventy-two hours was also analysed.

\section{Results}

Due to the time required to collect data from paper notes, there was a difference in numbers of pathways analysed. Within the first period of February to August 2015, seventy-nine patients' notes were reviewed, with two hundred and twenty-one electronic pathways being analysed for the second period between August 2016 and February 2017.

Overall, rates of completion of documentation improved following the introduction of the electronic NOF pathway across most domains. However, the numbers of patients receiving a fascia iliaca block within the emergency department reduced. The achievement of the BPT did slightly reduce however, but due the discrepancy between the numbers of pathways analysed it is not possible to know whether this is a true reflection on the efficacy of the paper pathway. Despite this the completion of the electronic NOF pathway did show an upward trend in the BPT achievement rate.

\section{Discussion}

As part of the NHS Five Year Forward View, there is a plan for a paperless system to be in place by 2020 . The use of more integrated technology in part aims to "reduce the administrative burden for care professionals" and by inputting data at the bedside, duplication can be reduced [7], documentation improved and patient care expedited. This closed loop audit has identified that electronic pathways such as this may be one example of an innovative technology that are required to achieve a paper free NHS. Overall, compliance of care within the different aspects of the BPT with a potential positive impact on patient
Table 1. Documentation completion rates before and after Introduction of electronic pathway.

\begin{tabular}{|c|c|c|c|c|}
\hline & $\begin{array}{c}\text { Pre- } \\
\text { introduction }\end{array}$ & (Paper) & $\begin{array}{l}\text { Post- } \\
\text { introduction }\end{array}$ & (Electronic) \\
\hline Category & $\begin{array}{l}\text { No. completed } \\
\qquad(\mathrm{n}=79)\end{array}$ & $\begin{array}{l}\text { Completion } \\
\text { Rates }\end{array}$ & $\begin{array}{l}\text { No. completed } \\
\quad(\mathrm{n}=221)\end{array}$ & $\begin{array}{l}\text { Completion } \\
\text { Rates }\end{array}$ \\
\hline Pain Score & 1 & $1.3 \%$ & 175 & $79.2 \%$ \\
\hline Pain Review & 54 & $68.4 \%$ & 174 & $78.7 \%$ \\
\hline X-ray results & 70 & $88.6 \%$ & 173 & $78.3 \%$ \\
\hline ECG results & 59 & $74.7 \%$ & 173 & $78.3 \%$ \\
\hline CXR results & 24 & $32.0 \%$ & 172 & $77.8 \%$ \\
\hline A\&E bloods & 61 & $77.2 \%$ & 171 & $77.4 \%$ \\
\hline Nerve Block & 30 & $38.0 \%$ & 65 & $29.4 \%$ \\
\hline $\begin{array}{c}\text { Previous } \\
\text { Medical History }\end{array}$ & 72 & $91.1 \%$ & 212 & $95.9 \%$ \\
\hline Head injury & 64 & $81.0 \%$ & 211 & $95.5 \%$ \\
\hline Social History & 71 & $89.9 \%$ & 211 & $95.5 \%$ \\
\hline $\begin{array}{l}\text { Abbreviated } \\
\text { Mental Test }\end{array}$ & 64 & $81.0 \%$ & 211 & $95.5 \%$ \\
\hline Observations & 36 & $45.6 \%$ & 212 & $95.9 \%$ \\
\hline $\begin{array}{l}\text { Pre-operation } \\
\text { bloods }\end{array}$ & 72 & $91.1 \%$ & 203 & $91.9 \%$ \\
\hline BPT achieved & 51 & $64.5 \%$ & 137 & $61.9 \%$ \\
\hline
\end{tabular}

care and indeed outcomes such as an improvement of orthogeriatrician reviews increased. Compliance with these standards has been shown to be beneficial to patients reducing mortality and improving outcomes. Between 2015 and 2016 when these audits took place, the value of BPT increased from $£ 890$ to $£ 1353$ making compliance potentially more valuable.

As well as there being a drive for the paperless system, there is an increasing awareness about the importance of adequate documentation [8] with more of a focus on what is written as being evidence of care. Within this evaluation, documentation improved across all domains (Table 1).

As a result, there were limitations to this audit due the nature of data collection from paper notes being time consuming and logistically more challenging.

\section{Conclusion}

The next stage of development of this pathway is to allow completed data to be automatically transferred into a format compatible for submission to the NHFD without the need for transfer by clinical 
Ward A and France J (2018) Streamlining patient care from the emergency department to discharge: Proof of concept of an electronic neck of femur pathway

support staff. The pathway is to be trialled at different sites, with the integration of different IT systems from emergency departments and wards.

\section{References}

1. Todd CJ, Freeman CJ, Camilleri-Ferrante C, Palmer CR, Hyder A, et al. (1995) Differences in mortality after fracture of hip: the East Anglian audit. BMJ 310: 904 908. [Crossref]

2. Keene GS, Parker MJ, Pryor GA (1993) Mortality and morbidity after hip fractures BMJ 307: 1248-1250. [Crossref]

3. Boereboom FT, Raymakers JA, Duursma SA (1992) Mortality and causes of death after hip fractures in the Netherlands. Neth J Med 41: 4-10. [Crossref]
4. Osteoporosis: assessing the risk of fragility fracture. Clinical guideline [CG146] NICE. Published August 2012, updated February 2017. Available at: https://www.nice. org.uk/guidance/cg146/chapter/introduction.

5. Wilson H, Harding, K and Sahota D. Best practice tariff for hip fracture- making ends meet. British Geriatric Society. 2010. Available at: www.bgs.org.uk/fallsresources-307/ subjectreference/fallsandbones/tariffhipfracture.

6. National Hip Fracture Database. 2016. Available at www.nhfd.co.uk.

7. NHS Digital. 2016. Available at https://digital.nhs.uk/article/549/National-InformationBoard-Paperless-2020.

8. Gutheil TG (2004) Fundamentals of Medical Record Documentation. Psychiatry (Edgmont) 1: 26-28. [Crossref]

Copyright: (2018 Ward A and France J. This is an open-access article distributed under the terms of the Creative Commons Attribution License, which permits unrestricted use, distribution, and reproduction in any medium, provided the original author and source are credited. 